OPEN ACCESS

Approved by:

Frontiers in Microbiology Editorial Office,

Frontiers Media SA, Switzerland

*Correspondence:

Ines Mandic-Mulec

ines.mandicmulec@bf.uni-lj.si

Specialty section:

This article was submitted to Microbial Physiology and Metabolism,

a section of the journal Frontiers in Microbiology

Received: 20 June 2018 Accepted: 21 June 2018 Published: 03 July 2018

Citation:

Spacapan M, Danevčič T and Mandic-Mulec I (2018) Corrigendum:

ComX-Induced Exoproteases Degrade ComX in Bacillus subtilis PS-216. Front. Microbiol. 9:1552. doi: 10.3389/fmicb.2018.01552

\section{Corrigendum: ComX-Induced Exoproteases Degrade ComX in Bacillus subtilis PS-216}

\author{
Mihael Spacapan, Tjaša Danevčič and Ines Mandic-Mulec* \\ Chair of Microbiology, Department of Food Science and Technology, Biotechnical Faculty, University of Ljubljana, Ljubljana, \\ Slovenia
}

Keywords: cell signaling, protease, quorum quenching, biofilms, degradative enzymes, quorum sensing, auto inducing signal, pellicles

\section{A corrigendum on}

\section{ComX-Induced Exoproteases Degrade ComX in Bacillus subtilis PS-216}

by Spacapan, M., Danevčič, T., and Mandic-Mulec, I. (2018). Front. Microbiol. 9:105. doi: $10.3389 /$ fmicb.2018.00105

In the original article, there was an error.

Mutants in amyE:: $\mathrm{P}_{a p r E}-g f p$ were constructed by transforming O8G57 genomic DNA (Veening et al., 2008) into appropriate PS-216 strains.

A correction has been made to Materials and methods, Strain Construction:

Mutants with $\mathrm{P}_{a p r E^{-}} g f p$ were constructed by transforming O8G57 genomic DNA (Veening et al., 2008) into appropriate PS-216 strains.

In the original article, there was a mistake in Table 1, Figure 1, Figure 3, Figure S2, Figure S5, and Figure $\mathrm{S} 7$ as published. The genotypic trait $\mathrm{P}_{\text {apre }}-g f p$ of the strains BM1142, BM1144, BM1443 and BM1448 was incorrectly stated as being amyE:: $\mathrm{P}_{a p r E^{-}}$gfp.

The authors apologize for these errors and state that this does not change the scientific conclusions of the article in any way.

The original article has been updated.

\section{REFERENCES}

Veening, J. W., Igoshin, O. A., Eijlander, R. T., Nijland, R., Hamoen, L. W., and Kuipers, O. P. (2008). Transient heterogeneity in extracellular protease production by Bacillus subtilis. Mol. Syst. Biol. 4:184. doi: 10.1038/msb.2008.18

Conflict of Interest Statement: The authors declare that the research was conducted in the absence of any commercial or financial relationships that could be construed as a potential conflict of interest.

Copyright $\odot 2018$ Spacapan, Danevčič and Mandic-Mulec. This is an open-access article distributed under the terms of the Creative Commons Attribution License (CC BY). The use, distribution or reproduction in other forums is permitted, provided the original author(s) and the copyright owner(s) are credited and that the original publication in this journal is cited, in accordance with accepted academic practice. No use, distribution or reproduction is permitted which does not comply with these terms. 